\title{
Differentiating of cross-reactions in patients with latex allergy with the use of ISAC test
}

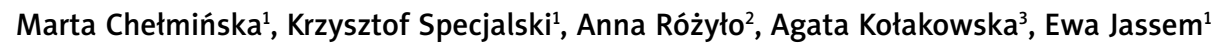 \\ ${ }^{1}$ Department of Allergology, Medical University of Gdansk, Gdansk, Poland \\ ${ }^{2}$ MEDI-LITE, Bielsko-Biala, Poland \\ ${ }^{3}$ Faculty of Electronics, Telecommunications and Informatics, Gdansk University of Technology, Gdansk, Poland
}

Adv Dermatol Allergol 2016; XXXIII (2): 120-127

DOI: 10.5114/ada.2016.59154

\begin{abstract}
Introduction: Differentiating between cross-reactivity and double sensitization is still a challenging issue in allergology.

Aim: To differentiate cross-reactions accompanying latex allergy with the use of the ISAC test.

Material and methods: Thirty-nine patients reporting immediate allergic reactions to latex were enrolled into the study (group A). The control group was comprised of 41 patients with allergic diseases not associated with latex (group B) and 20 healthy individuals (group C). Their history was recorded and skin prick tests were performed with latex, airborne and food allergens. Specific IgE against food allergens, latex (k82) and recombined latex allergens were determined. ImmunoCAP ISAC test was performed with 103 molecules.

Results: Sensitization to latex was found by means of skin tests in 16 cases and slgE against latex was revealed in 12 cases (including 10 positive in both SPT and slgE). In the ISAC test antibodies against recombined latex allergens were found in 8 patients with rHev b 6 as the most common. All the patients positive for rHev b 1, 5, 6, 8 had allergy or asymptomatic sensitization to food allergens cross-reacting with latex. Some reactions could not have been differentiated due to the lack of allergens in the ISAC test. Others, not related to latex-fruits syndrome were explained by cross-reactivity with other profilins or PR-10 proteins.

Conclusions: ImmunoCAP ISAC test could be useful in differentiating between cross-reactions and double sensitizations. However, in the case of latex its advantages are limited due to a small panel of allergens.
\end{abstract}

Key words: latex allergy, cross-reactivity, ISAC test.

\section{Introduction}

Prevalence of sensitization to latex is estimated to be about $1 \%$, but only $0.1 \%$ of the European population develop immediate reactions after exposure [1, 2]. The risk factors for sensitization include frequent exposure at a workplace (health care facilities, gum industry etc.) and repeated diagnostic or therapeutic medical procedures $[3,4]$. Although the first case of anaphylaxis induced by latex was described by Stern in 1927, the problem started to arise when medical gloves were introduced into everyday practice, particularly in the 1980s [5].

Allergy to latex can be manifested either by contact dermatitis (type IV, delayed reaction) or immediate, anaphylactic (type I) reaction, which is more dangerous and may be fatal. Skin, nose and conjunctiva are the most frequent target organs [6]. In 30-80\% of sensitized individuals, cross-reactivity with certain foods is observed, particularly with banana, avocado and papaya (50\%), chestnut, kiwi and tomato (30-50\%), celery, apple, pineapple and melon (30\%) [7-11]. This is due to similarity of epitopes binding specific IgE. Allergens responsible for development of cross-reactions are: Hev b 8 (profilin) - in relation to kiwi, banana, apple, pineapple, tomato, celery; Hev b 11 (class I chitinase) - avocado, banana, chestnut; Hev b 12 (lipid transfer protein) - kiwi, banana, apple, celery, hazelnut, walnut, peach; Hev b 7 (patatin-like protein) - potato.

Diagnosis of latex allergy is usually based on anamnesis, skin prick tests and patch tests, and specific IgE determination. Although very useful in everyday practice, these methods do not make it possible to distinguish

Address for correspondence: Krzysztof Specjalski MD, Department of Allergology, Medical University of Gdansk, 7 Debinki St, 80-952 Gdansk, Poland, phone: +48 608631 547, fax: +48 5834916 25, e-mail: specjalski@gumed.edu.pl Received: 12.09 .2014 , accepted: 25.12.2014. 
between double sensitizations and cross-reactions. Understanding of the hypersensitivity mechanism would be useful as it could influence its management.

\section{Aim}

The aim of this study was to differentiate cross-reactions accompanying latex allergy with the use of the ISAC test.

\section{Material and methods}

Thirty-nine patients reporting immediate allergic reactions to latex were enrolled into the study (group A). The control group was comprised of 41 patients with allergic diseases not associated with latex (group B) and 20 healthy individuals (group C). The patients were recruited in the Department of Allergology, Medical University of Gdansk and healthy controls - among hospital employees. Characteristics of the study population are presented in Table 1.

In all subgroups, exclusion criteria included pregnancy and serious medical conditions which could, in our opinion, affect safety or reliability of planned procedures (current infection, exacerbation of allergic disease, inability to discontinue antihistamines etc.).

In all study participants, their history was recorded including symptoms of latex allergy and other allergic conditions. Skin prick tests were performed with latex and common airborne allergens (Allergopharma, Reinbeck, Germany) as well as food allergens (banana, kiwi, avocado, potato, tomato, celery, carrot, paprika, walnut, hazelnut, peanut, apple) (Stallergenes, Anthony, France) in accordance with EAACI guidelines [12]. Then, blood was collected for determining of specific IgE and the ISAC test. Specific lgE against banana, kiwi, avocado, potato, tomato, celery, carrot, paprika, walnut, hazelnut, peanut, apple, latex and recombined latex allergens: rHev b 1, rHev b 3,
rHev b 5, rHev b 6.01, rHev b 8, rHev b 9, rHev b 11 were measured by means of ImmunoCAP Phadia System (Phadia, Uppsala, Sweden). ImmunoCAP ISAC test (Phadia, Uppsala, Sweden) was performed with 103 molecules including allergens of latex (rHev b 1, rHev b 3, rHev b 5, rHev b 6, rHev b 8), kiwi (nAct d 1, nAct d 2, nAct d 5, nAct d 8), celery (rApi g 1), carrot (rDau c 1), apple (rMal d 1), peach (rPru p 1, nPru p 3), peanut (nAra h 1, nAra h 2, nAra h 3, nAra h 8), hazelnut (rCor a 1.0401, rCor a 8, nCor a 9), pineapple (nAna c 2) etc. The results were expressed in ISAC standardized units (ISU) as well as in classes: class $0-<0.3$ ISU; class $1-0.3-1.0$ ISU; class 2-1.0-15.0 ISU; class 3 - > 15 ISU.

All the participants gave written informed consent before the tests. The protocol was approved by the Independent Bioethics Committee of Medical University of Gdansk.

\section{Statistical analysis}

In statistical analysis, $\chi^{2}$ test with Yates' correction was applied for comparison of qualitative variables between the study groups. Value of $p<0.05$ was considered significant. Software Statistica 8.0 was applied for the calculations (StatSoft, Tulsa, USA).

\section{Results}

Thirty-nine patients with a history of latex allergy were enrolled into this study. Most of them reported contact urticaria (38 patients; 97\%), rhinitis (8 patients; 20.5\%), conjunctivitis (8 patients; $20.5 \%$ ) and dyspnoea (7 patients; 18\%) after exposure. In 3 cases, an anaphylactic shock was documented. Fourteen of these patients reported also reactions to certain food allergens, mostly to banana, kiwi fruit, apple, walnut and hazelnut (Table 2). In group B, food allergy was reported by 16 patients with hazelnut and walnut as the most common allergens.

Table 1. Study population characteristics

\begin{tabular}{|c|c|c|c|c|}
\hline Parameter & & $\begin{array}{l}\text { Group A } \\
(n=39)\end{array}$ & $\begin{array}{l}\text { Group B } \\
(n=41)\end{array}$ & $\begin{array}{l}\text { Group C } \\
(n=20)\end{array}$ \\
\hline \multicolumn{5}{|l|}{ Age [years]: } \\
\hline \multicolumn{2}{|l|}{ Range } & $18-68$ & $18-59$ & $21-69$ \\
\hline \multicolumn{2}{|l|}{ Mean } & 39.7 & 32.6 & 38.7 \\
\hline \multicolumn{2}{|l|}{ Gender (women : men) } & $35: 4$ & $21: 20$ & $16: 4$ \\
\hline \multirow{7}{*}{$\begin{array}{l}\text { Concomitant allergic } \\
\text { diseases }\end{array}$} & Asthma & $17(43.6 \%)$ & $32(78 \%)$ & - \\
\hline & Rhinitis & $24(61.5 \%)$ & $36(87.8 \%)$ & - \\
\hline & Conjunctivitis & $21(53.8 \%)$ & $29(70.7 \%)$ & - \\
\hline & Atopic dermatitis & $10(25.6 \%)$ & $7(17.1 \%)$ & - \\
\hline & Food allergy & $19(48.7 \%)$ & $23(56.1 \%)$ & - \\
\hline & Insect venom allergy & 7 (17.9\%) & $5(12.2 \%)$ & - \\
\hline & Drug allergy & $14(35.9 \%)$ & $16(39 \%)$ & - \\
\hline
\end{tabular}


Table 2. Prevalence of positive skin prick tests (SPT) and specific IgE (slgE) to latex (k82) and food allergens in the study groups

\begin{tabular}{|c|c|c|c|c|c|c|c|c|}
\hline \multirow[t]{2}{*}{ Allergen } & \multicolumn{2}{|c|}{ History } & \multicolumn{3}{|c|}{ SPT } & \multicolumn{3}{|c|}{ slgE } \\
\hline & Group A & Group B & Group A & Group B & Group C & Group A & Group B & Group C \\
\hline Latex & 39 (100\%) & $0(0 \%)$ & $13(33.3 \%)$ & $3(7.3 \%)$ & $0(0 \%)$ & 7 (17.9\%) & $5(12.2 \%)$ & $0(0 \%)$ \\
\hline Banana & 7 (17.9\%) & $1(2.4 \%)$ & $8(20.5 \%)$ & 7 (17.0\%) & $1(5.0 \%)$ & $4(10.3 \%)$ & $6(14.6 \%)$ & $0(0 \%)$ \\
\hline Kiwi fruit & $8(20.5 \%)$ & $3(7.3 \%)$ & $10(25.6 \%)$ & $6(14.6 \%)$ & $0(0 \%)$ & $3(7.7 \%)$ & $4(9.8 \%)$ & $0(0 \%)$ \\
\hline Avocado & 5 (12.8\%) & $1(2.4 \%)$ & $8(20.5 \%)$ & $6(14.6 \%)$ & $1(5.0 \%)$ & $3(7.7 \%)$ & $9(21.2 \%)$ & $0(0 \%)$ \\
\hline Potato & $3(7.7 \%)$ & $2(4.9 \%)$ & 7 (17.9\%) & 8 (19.5\%) & 2 (10.0\%) & $2(5.1 \%)$ & 7 (17.1\%) & $0(0 \%)$ \\
\hline Tomato & $2(5.1 \%)$ & $4(9.8 \%)$ & $8(20.5 \%)$ & $6(14.6 \%)$ & $1(5.0 \%)$ & $3(7.7 \%)$ & 7 (17.1\%) & $0(0 \%)$ \\
\hline Celery & $3(7.7 \%)$ & $5(12.2 \%)$ & $8(20.5 \%)$ & $10(24.4 \%)$ & $1(5.0 \%)$ & $2(5.1 \%)$ & 7 (17.1\%) & $0(0 \%)$ \\
\hline Carrot & $1(2.6 \%)$ & $2(4.9 \%)$ & 5 (12.8\%) & $5(12.2 \%)$ & $1(5.0 \%)$ & $1(2.6 \%)$ & $8(19.5 \%)$ & $0(0 \%)$ \\
\hline Paprika & $0(0 \%)$ & $2(4.9 \%)$ & 7 (17.9\%) & 7 (17.0\%) & $3(15.0 \%)$ & $1(2.6 \%)$ & $5(12.2 \%)$ & $0(0 \%)$ \\
\hline Walnut & 6 (15.4\%) & 7 (17.1\%) & 9 (23.1\%) & $4(9.8 \%)$ & 2 (10.0\%) & $0(0 \%)$ & $4(9.8 \%)$ & $0(0 \%)$ \\
\hline Peanut & $0(0 \%)$ & $2(4.9 \%)$ & 6 (15.4\%) & $6(14.6 \%)$ & $3(15.0 \%)$ & $1(2.6 \%)$ & $3(7.3 \%)$ & $0(0 \%)$ \\
\hline Hazelnut & $6(15.4 \%)$ & $8(19.5 \%)$ & 9 (23.1\%) & 8 (19.5\%) & $2(10.0 \%)$ & $6(15.4 \%)$ & $13(31.7 \%)$ & $0(0 \%)$ \\
\hline Apple & 7 (17.9\%) & $4(9.8 \%)$ & $1(2.6 \%)$ & $2(4.88 \%)$ & $0(0 \%)$ & $3(7.7 \%)$ & $4(9.8 \%)$ & $0(0 \%)$ \\
\hline
\end{tabular}

Histories of food allergy were partly confirmed by skin prick tests. Their sensitivity was between $27 \%$ and $63 \%$ with relatively high values for celery $(63 \%)$, banana (50\%) and hazelnut (50\%). Their specificity was the highest for banana (87\%), walnut (87\%), and hazelnut (86\%). In contrast, no true positive results were obtained for carrot, paprika and apple. The number of positive SPTs was significantly higher in patients with clinical symptoms of latex allergy (group A) compared to patients with other allergic conditions (group B) $(p=0.0086)$. Such differences were not observed in results of slgE. The sensitivity of their determination was 9-43\% and specificity - 88$98 \%$. The highest values were obtained for walnut, kiwi fruit and potato (93-98\%).

Sensitization to latex was found by means of SPTs in 13 cases from group A (33.3\%) and 3 cases from group B (7.3\%). SlgE against latex was revealed in 7 patients from group A (17.9\%) and 5 from group B. As far as recombined allergens are concerned, antibodies against Hev b 6.02 and Hev b 8 were most often found (Table 3). In the ISAC test, antibodies against recombined latex allergens were found in 8 patients ( 6 in group A, 2 in group B) with rHev b 6 as the most common (4 patients).

\section{Relations between positive skin prick test (SPT) with latex and food allergy}

Out of 16 patients with positive SPTs with latex, 11 reported food allergy (mostly to hazelnut, kiwi, walnut, banana). In 8 participants, the history was confirmed by skin tests and/or slgE. In the group that did not report any food allergies, 4 were positive in SPT and/or slgE with food and only 1 patient was negative in both SPTs and slgE.

\section{Relations between slgE to latex and food allergy}

slgE to latex (k82) were positive in 12 patients. Nine of them had a history of food allergy confirmed by SPT and/or slgE. Three subjects had a negative history, including two positive in SPTs (kiwi and celery). SIgEs against recombinant latex allergens were found by means of ImmunoCAP in 4 patients for Hev b 6.01 (3 with a positive history of food allergy, 4 with positive SPTs and 3 with positive slgEs), in 5 patients for Hev b 6.02 (4 with a positive history of food allergy, 5 with positive SPTs, 2 with positive slgEs) and in 5 patients for Hev b 8 ( 3 with a positive history, 4 with positive SPTs, 5 with positive slgEs).

\section{Relations between positive latex responses in the ISAC test and food allergy}

All the patients positive in the ISAC test for rHev b 1 , 5, 6, 8 had food allergy or were asymptomatically sensitized. rHev b 5 was positive in one patient who had latex allergy confirmed by SPT and sIgE. Despite no history of food allergy the patient had positive SPTs with kiwi, avocado, potato, tomato, celery, paprika, peanut and hazelnut. The only positive result for $\mathrm{rHev} b 8$ was found in group $B$. The patient, with chronic asthma, rhinitis and no history of food allergy, was positive in SPT with grass, trees, weeds and walnut, in slgE - with latex ( $k 82$ and rHev b 8), banana, avocado, tomato, celery and carrot, in ISAC - rBet v 2, Phl p 1, 2, 4. Thus, similarity of profilins Bet $\vee 2$ and Hev b 8 could explain such reactivity. Four 
positive results for rHev b 6 were obtained in patients with latex allergy 3 of whom had food allergy confirmed by SPT and/or IgE (kiwi, hazelnut, walnut, banana, potato) and 1 was found to be asymptomatically sensitized to kiwi and hazelnut.

\section{Latex-fruits and pollens-fruits cross-reactions}

In patients with confirmed food allergy several patterns of reactivity were found. As far as banana is concerned, allergy was confirmed in 4 patients - one of them was positive in ImmunoCAP for rHev b 8 and $r$ Hev b 6.01, another one - for rHev b 6.01, rHev b 6.02, rHev b 11 in ImmunoCAP and $r$ Hev $b 6$ in the ISAC test.

Out of 11 patients reporting hypersensitivity to kiwi fruit, 3 were positive in SPT and/or slgE, including 2 who were also positive for latex (one for $\mathrm{rHev}$ b 6.01 and $\mathrm{rHev}$ b 8 in ImmunoCAP and one for rHev b 6.01, rHev b 6.02, rHev b 11 in ImmunoCAP and rHev b 6 in ISAC). In ISAC test four kiwi allergens were included (nAct d 1, 2, 5, 8). We found one positive result for nAct d 1, 2, 8 and none for nAct $d$ 5. Patients positive for nAct 1, 8 tolerated kiwi. The patient with positive result for nAct $\mathrm{d} 2$ reported several pollen and food allergies but the latter were not confirmed either by SPT or ImmunoCAP.

The highest rate of confirmed food allergies was obtained for hazelnut (8/14). Two patients had allergy to pollens and hazelnut with no concomitant latex allergy. ISAC tests revealed in both cases sensitization to Bet $v 1$ homologues (PR-10 proteins) which are known to be responsible for numerous pollens-fruits reactions. Six patients had concomitant latex allergy including 2 positive for rHev b 6 in ISAC test and 5 positive in a least one determination in ImmunoCAP. One of latex positive patients had no concomitant allergies and responded in ISAC to rHev b 6, in ImmunoCAP - k82, Hev b 6.01, Hev b 6.02, Hev b 11. Five of latex responders had concomitant allergy to pollens with $(n=2)$ or without $(n=3)$ positive Bet $v 1$.

Clinical data and test results of patients with a history of food hypersensitivity are presented in detail in Table 4.

\section{Discussion}

Usefulness of the ISAC test has been demonstrated in several studies. Although varied in terms of inclusion criteria, application of additional tests and a panel of allergens analysed, they made it possible to understand mechanisms of allergic reactions in participants by indicating culprit determinants and, as a consequence, confirming cross-reactivity [13-16]. Scala et al. demonstrated relations between 75 components of ISAC in 23077 patients [17]. Ott et al. showed a high prevalence of sensitization to PR-10 proteins (allergens of birch, alder, apple, celery etc.) in patients with atopic dermatitis and allergic asthma $[18,19]$. As far as latex allergy is con-
Table 3. Prevalence of slgE against latex allergens in ImmunoCAP and ImmunoCAP ISAC tests in three study subgroups

\begin{tabular}{|c|c|c|c|c|}
\hline & Allergen & Group A & Group B & Group C \\
\hline \multirow{7}{*}{$\frac{\omega}{\omega}$} & Hev b 1 & $0(0 \%)$ & $1(2.4 \%)$ & $0(0 \%)$ \\
\hline & Hev b 3 & $0(0 \%)$ & $1(2.4 \%)$ & $0(0 \%)$ \\
\hline & Hev b 5 & $1(2.6 \%)$ & $1(2.4 \%)$ & $0(0 \%)$ \\
\hline & Hev b 6.01 & $3(7.7 \%)$ & $1(2.4 \%)$ & $0(0 \%)$ \\
\hline & Hev b 6.02 & 4 (10.3\%) & $1(2.4 \%)$ & $0(0 \%)$ \\
\hline & Hev b 8 & $1(2.6 \%)$ & $4(9.8 \%)$ & $0(0 \%)$ \\
\hline & Hev b 9 & $0(0 \%)$ & $1(2.4 \%)$ & $0(0 \%)$ \\
\hline \multirow{6}{*}{ 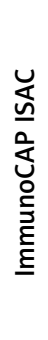 } & Hev b 11 & $1(2.6 \%)$ & $1(2.4 \%)$ & $0(0 \%)$ \\
\hline & rHev b 1 & $0(0 \%)$ & $1(2.4 \%)$ & $0(0 \%)$ \\
\hline & rHev b 3 & 1 (2.6\%) & $0(0 \%)$ & $0(0 \%)$ \\
\hline & rHev b 5 & $1(2.6 \%)$ & $0(0 \%)$ & $0(0 \%)$ \\
\hline & rHev b 6 & 4 (10.3\%) & $0(0 \%)$ & $0(0 \%)$ \\
\hline & rHev b 8 & $0(0 \%)$ & $1(2.4 \%)$ & $0(0 \%)$ \\
\hline
\end{tabular}

cerned, Raulf-Heimsoth et al. analyzed 19 patients with slgE against chestnut and latex. rHev b 6.01 was found in $58 \%$, rHev b $5-32 \%$, rHev b $12-30.8 \%$, rHev b 7.02 and $11-21 \%$, rHev b $1-10.5 \%$ and rHev b 8 in $47 \%$ of subjects. A positive result for $\mathrm{rHev} b 8$ (profilin) was interpreted as the cause of cross-reactivity [20].

During the recruitment into this study, the ISAC test's manufacturer changed the panel of allergens limiting latex allergens to Hev b 1, 3, 5, 6 and 8. The withdrawn allergens included Hev b 7 - patatin-like protein necessary to differentiate cross-reactions with potato, Hev b 11 - class I chitinase responsible for reactions with avocado, banana and chestnut, Hev b 9 (enolase) and Hev b 10 (superoxide dismutase $\mathrm{Mn}$ ) - important in cross-reactions with fungi. Some of the significant food allergens, including banana, avocado, potato, tomato, were not included, either. Apart from Hev b 8, a family of profilins was represented only by pollens' allergens: Bet $\vee 2$, Mer a 1 , Ole e 2, Phl p 12. No important food profilin was included e.g. Mal d 4, Api g 4 Acd d 9, Ara h 5. Another family important for cross-reactivity - lipid transfer proteins (LTP) - is represented by 4 allergens only - Art v 3, Cor a 8, Pru p 3, Par j 2. The only thaumatin-like protein is kiwi's Act $d$ 2. In contrast, PR-10 proteins are richly represented by Bet v 1 homologues: Act d 8, Mal d 1, Ara h 8, Cor a 1.0101, Cor a 1.0401 etc. Although they do not cross-react with latex, they are useful for assessment of pollen-fruit reactions.

Lack of the aforementioned allergens is the major limitation of this study as it did not allow us to confirm all the possible cross-reactions. For the future studies in 
Table 4. Results of skin prick tests (SPT), ImmunoCAP and ISAC tests in patients with a history of food allergy

\begin{tabular}{|c|c|c|c|c|c|c|c|c|c|c|c|c|c|}
\hline \multirow[t]{2}{*}{$\begin{array}{l}\text { No. of } \\
\text { cases }\end{array}$} & \multicolumn{2}{|c|}{$\begin{array}{l}\text { History } \\
\text { of allergy }\end{array}$} & \multicolumn{3}{|c|}{ SPT } & \multicolumn{6}{|c|}{ ImmunoCAP } & \multicolumn{2}{|c|}{ ISAC } \\
\hline & Latex & Pollens & Latex & Food & Pollens & $\begin{array}{l}\text { Latex } \\
\text { k82 }\end{array}$ & $\begin{array}{l}r \mathrm{Hev} \\
\text { b } 6.01\end{array}$ & $\begin{array}{l}\text { rHev } \\
\text { b } 6.02\end{array}$ & $\begin{array}{c}\text { rHev } \\
\text { b } 8\end{array}$ & $\begin{array}{l}\text { rHev } \\
\text { b } 11\end{array}$ & Food & $\begin{array}{l}\text { rHev } \\
\text { b } 6\end{array}$ & Bet $v 1$ \\
\hline \multicolumn{14}{|c|}{ Banana } \\
\hline 1 & + & + & + & + & - & + & + & - & - & - & - & - & - \\
\hline 2 & + & + & - & - & + & - & - & - & - & - & - & - & - \\
\hline 2 & + & + & - & - & - & - & - & - & - & - & - & - & - \\
\hline 1 & + & + & + & + & + & + & + & - & + & - & + & - & - \\
\hline 1 & + & + & + & + & - & + & + & + & - & + & + & + & - \\
\hline 1 & + & + & + & + & - & - & - & - & - & - & - & - & - \\
\hline \multicolumn{14}{|c|}{ Kiwi fruit } \\
\hline 1 & + & + & + & - & - & + & + & - & - & - & - & - & - \\
\hline 1 & + & + & - & - & + & - & - & - & - & - & - & - & - \\
\hline 1 & - & + & - & - & + & - & - & - & - & - & - & - & - \\
\hline 1 & + & + & - & - & - & - & - & - & - & - & - & - & - \\
\hline 1 & + & + & + & - & + & + & - & - & - & - & - & + & + \\
\hline 1 & + & + & + & + & + & + & + & - & + & - & - & - & - \\
\hline 1 & + & + & - & - & + & - & - & - & - & - & - & - & - \\
\hline 1 & + & + & - & + & - & - & - & - & - & - & + & - & - \\
\hline 1 & + & + & + & + & - & + & + & + & - & + & - & + & - \\
\hline 1 & + & + & + & - & - & - & - & - & - & - & - & - & - \\
\hline 1 & - & + & - & - & - & - & - & - & - & - & - & - & - \\
\hline \multicolumn{14}{|c|}{ Avocado } \\
\hline 2 & + & + & - & - & + & - & - & - & - & - & - & - & - \\
\hline 2 & + & + & - & - & - & - & - & - & - & - & - & - & - \\
\hline 1 & + & + & + & + & + & + & + & - & + & - & + & - & - \\
\hline 1 & + & + & + & + & - & - & - & - & - & - & - & - & - \\
\hline \multicolumn{14}{|c|}{ Potato } \\
\hline 1 & + & + & + & - & + & + & - & - & - & - & - & + & + \\
\hline 1 & + & + & + & + & + & + & + & - & + & - & + & - & - \\
\hline 1 & + & + & - & - & + & - & - & - & - & - & - & - & - \\
\hline 1 & + & + & + & + & - & + & + & + & - & + & + & + & - \\
\hline 1 & - & + & - & - & - & - & - & - & - & - & - & - & - \\
\hline \multicolumn{14}{|c|}{ Tomato } \\
\hline 1 & + & + & + & + & - & + & + & - & - & - & - & - & - \\
\hline 2 & - & + & - & - & + & - & - & - & - & - & - & - & - \\
\hline 1 & + & + & - & - & + & - & - & - & - & - & - & - & - \\
\hline 1 & + & + & - & - & + & - & - & - & - & - & - & - & + \\
\hline 1 & - & + & - & + & + & - & - & - & - & - & - & - & - \\
\hline \multicolumn{14}{|c|}{ Carrot } \\
\hline 1 & + & + & + & - & + & - & - & - & - & - & - & - & - \\
\hline 1 & + & + & - & - & + & - & - & - & - & - & - & - & - \\
\hline 1 & - & + & - & - & + & - & - & - & - & - & - & - & - \\
\hline \multicolumn{14}{|c|}{ Paprika } \\
\hline 1 & + & + & - & - & + & - & - & - & - & - & - & - & - \\
\hline 1 & - & + & + & - & + & - & - & - & - & - & - & - & - \\
\hline
\end{tabular}


Table 4. Cont.

\begin{tabular}{|c|c|c|c|c|c|c|c|c|c|c|c|c|c|}
\hline \multirow[t]{2}{*}{$\begin{array}{l}\text { No. of } \\
\text { cases }\end{array}$} & \multicolumn{2}{|c|}{$\begin{array}{l}\text { History } \\
\text { of allergy }\end{array}$} & \multicolumn{3}{|c|}{ SPT } & \multicolumn{6}{|c|}{ ImmunoCAP } & \multicolumn{2}{|c|}{ ISAC } \\
\hline & Latex & Pollens & Latex & Food & Pollens & $\begin{array}{c}\text { Latex } \\
\text { k82 }\end{array}$ & $\begin{array}{l}\text { r Hev } \\
\text { b } 6.01\end{array}$ & $\begin{array}{l}\mathrm{rHev} \\
\text { b } 6.02\end{array}$ & $\begin{array}{l}\text { rHev } \\
\text { b } 8\end{array}$ & $\begin{array}{l}\mathrm{rHev} \\
\text { b } 11\end{array}$ & Food & $\begin{array}{l}\mathrm{rHev} \\
\mathrm{b} 6\end{array}$ & Bet $v 1$ \\
\hline \multicolumn{14}{|c|}{ Celery } \\
\hline 1 & - & + & - & + & + & - & - & - & - & - & + & - & - \\
\hline 1 & + & + & + & - & + & + & + & - & + & - & - & - & - \\
\hline 2 & + & + & - & - & + & - & - & - & - & - & - & - & - \\
\hline 1 & - & + & - & + & + & - & - & - & - & - & - & - & - \\
\hline 1 & - & + & - & + & + & - & - & - & - & - & - & - & + \\
\hline 1 & + & + & + & + & - & + & + & + & - & + & - & + & - \\
\hline 1 & - & + & - & + & + & + & - & - & - & - & + & - & - \\
\hline \multicolumn{14}{|c|}{ Peanut } \\
\hline 1 & - & + & - & - & + & - & - & - & - & - & - & - & - \\
\hline 1 & - & + & - & - & + & - & - & - & - & - & - & - & + \\
\hline \multicolumn{14}{|c|}{ Hazelnut } \\
\hline 1 & - & + & - & - & + & - & - & - & - & - & - & - & - \\
\hline 1 & - & + & - & - & + & - & - & - & - & - & - & - & + \\
\hline 1 & + & + & + & + & + & + & - & - & - & - & + & + & + \\
\hline 1 & + & + & + & - & + & + & + & - & + & - & - & - & - \\
\hline 1 & + & + & - & - & + & - & - & - & - & - & - & - & - \\
\hline 1 & - & + & - & + & + & - & - & - & - & - & + & - & + \\
\hline 1 & - & + & - & - & + & - & - & - & - & - & + & - & + \\
\hline 1 & + & + & + & + & + & - & - & - & - & - & - & - & - \\
\hline 1 & + & + & + & + & - & + & + & + & - & + & - & + & - \\
\hline 1 & - & + & - & + & + & + & - & - & - & - & + & - & - \\
\hline 1 & + & - & - & - & - & - & - & - & - & - & - & - & - \\
\hline 1 & + & + & + & + & + & - & - & - & - & - & + & - & + \\
\hline 1 & - & + & + & + & + & + & - & - & - & - & + & - & - \\
\hline 1 & - & + & - & - & - & - & - & - & - & - & - & - & - \\
\hline \multicolumn{14}{|c|}{ Walnut } \\
\hline 1 & - & + & - & - & + & - & - & - & - & - & - & - & - \\
\hline 1 & - & + & - & - & + & - & - & - & - & - & - & - & + \\
\hline 1 & + & + & + & - & + & + & - & - & - & - & - & + & + \\
\hline 1 & + & + & + & - & + & + & + & - & + & - & - & - & - \\
\hline 1 & + & + & - & - & + & - & - & - & - & - & - & - & - \\
\hline 2 & + & + & + & - & + & - & - & - & - & - & - & - & + \\
\hline 1 & + & + & + & - & + & - & - & - & - & - & - & - & - \\
\hline 1 & + & + & + & + & - & + & + & + & - & + & - & + & - \\
\hline 1 & - & + & - & + & + & + & - & - & - & - & + & - & - \\
\hline 1 & + & - & - & - & - & - & - & - & - & - & - & - & - \\
\hline 1 & - & + & + & + & + & + & - & - & - & - & + & - & - \\
\hline 1 & - & + & - & - & - & - & - & - & - & - & - & - & - \\
\hline \multicolumn{14}{|c|}{ Apple } \\
\hline 2 & + & + & - & - & + & - & - & - & - & - & - & - & - \\
\hline 1 & + & + & - & - & + & - & - & - & - & - & - & - & + \\
\hline 2 & + & + & - & - & - & - & - & - & - & - & - & - & - \\
\hline 1 & - & + & - & - & + & - & - & - & - & - & + & - & - \\
\hline 1 & + & + & + & - & + & + & + & - & + & - & - & - & - \\
\hline 1 & + & + & + & - & + & - & - & - & - & - & - & - & - \\
\hline 1 & + & + & + & - & - & - & - & - & - & - & - & - & - \\
\hline 1 & - & + & - & - & - & - & - & - & - & - & - & - & - \\
\hline 1 & - & + & - & - & + & - & - & - & - & - & - & - & + \\
\hline
\end{tabular}


this area it would be useful to include LTPS: Hev b 12, Mus a 3, Api g 2, Act d 10, Ara h 9, Mal d 3, Lyc e 3, class I chitinases: Hev b 11, Pers a 1, Mus a 2 and thaumatin-like proteins: Mus a 4, Mal d 2, Pru p 2. Some of the missing allergens which could be useful for interpretation of cross-reactions may be determined separately with the use of ImmunoCAP. This is possible for Hev b 1, 3, 5, 6.01, 6.02, 8, 9, 11, Bet v 2, Phl p 12, Art v 3, Ara h 9 etc.

We included into this study 39 patients reporting immediate symptoms of latex allergy (group A), 41 allergic patients with no history of reaction to latex (group B) and 20 healthy controls (group C). Some participants (group A - 14, group B - 16) had also a history of food hypersensitivity which could result from cross-reactions between latex and fruit or pollens and fruit allergens. SPTs confirmed sensitization to latex in 16 and slgE - in 12 patients only. The possible reasons for such overestimation were misinterpretation of symptoms by patients, reactions to other allergens or another mechanism of true latex allergy (i.e. T-cells mediated reactions). The low proportion of positive results was also found with food allergens. However, we have not performed doubleblind placebo-controlled food challenges and based the diagnosis on SPT and slgE that are not usually found in all cases of allergy to fruits [21].

slgEs against latex allergens were found in symptomatic and asymptomatic patients with the following frequency: $\mathrm{k} 82-18 \%$ and $12.2 \%$, rHev b $5-2.6 \%$ and 2.4\%; rHev b $6.01-7.7 \%$ and $2.4 \%$; rHev b $6.02-10.3 \%$ and $2.4 \%$; rHev b $11-2.6 \%$ and $2.4 \%$, rHev b $8-2.6 \%$ and $9.8 \%$, respectively. A higher prevalence of slgE to profilin rHev b 8 in cases of clinically silent sensitization has been observed before $[14,16]$.

In group A, 4 patients were positive in the ISAC test for rHev b 6, one for rHev b 3 and 5, in the latter one 1 patient was positive for $r \mathrm{Hev} b 1$ and 8 . This is in contrast to the study of Ott et al. who found positive results for rHev b 6.02 in $69 \%$, rHev b 5 - in $44 \%$, rHev b $8-31 \%$, rHev b $1-23 \%$ and rHev b 3 - in $2 \%$ of patients with latex allergy confirmed by SPT [16]. Similarly, Ebo et al. found a high prevalence of antibodies against rHev $b 5$ and/or 6.02 (75\%) and relatively low against rHev b 1 and 3 (18\%, $14 \%$ respectively) in the group of 22 patients with positive SPT and slgE to latex [14]. We have not confirmed the fact of frequent co-existence of Hev b 11 and Hev b 6.02 either, what probably resulted from a low number of positive results.

Almost all the patients with latex allergy either had a history of food allergy or were asymptomatically sensitized. Banana, avocado, potato and tomato were the most significant allergens. In some cases we managed to explain mechanisms of cross-reactivity. IgE against rHev b 11 was found in patients reacting to banana and avocado. IgE against rHev b 8 was revealed in cases of allergy to banana, kiwi fruit, avocado, potato and celery i.e. food containing homologous profilins [21, 22]. Profilin
Bet $v 2$ was positive in two patients, both with pollens allergy, with no history of latex or food allergy, but positive for rHev b 8 in ImmunoCAP.

Finally, the ISAC test made it possible to find alternative cross-reactions resulting in polyvalent allergy. In our study 9 cases of food allergy were associated with PR-10 proteins (Bet $v 1$ homologues).

\section{Conclusions}

ImmunoCAP ISAC test based on the CRD technique could be a valuable addition to the traditional allergological work-up, particularly in differentiating between latexfruits and pollen-fruits cross-reactions. However, in cases of latex allergy, its advantages are significantly limited due to a small panel of available allergens.

\section{Acknowledgments}

The work should be attributed to the Department of Allergology, Medical University of Gdansk. Publication has been financed by Medical University of Gdansk, grant no. ST-553.

\section{Conflict of interest}

The authors declare no conflicts of interest.

\section{References}

1. Turjanmaa K, Alenius H, Makinen-Kiljunen S, et al. Natural rubber latex allergy. Allergy 1996; 51: 593-602.

2. Turjanmaa K. Allergy to natural rubber latex: a growing problem. Ann Med 1994; 26: 297-300.

3. Kowalski ML, Łucka D, Kowalewski M. Objawy alergii na wyroby lateksowe wśród lekarzy i pielęgniarek oddziałów zabiegowych. Medycyna 2000 1995; 53: 45-8.

4. Porri F, Lemiere C, Birnbaum J, et al. Association between latex sensitization and repeated latex exposure in children. Anesthesiology 1997; 86: 599-602.

5. Stern G. Überempfindlichkeit gegen Kautschuk als Ursache von Urticaria und Quinckeschem Ödem. Klein Wochenschr 1927; 6: 1096-7.

6. Jager D, Kleinhans D, Czuppon AB, Baur X. Latex-specific proteins causing immediate-type cutaneous, nasal, bronchial and systemic reactions. J Allergy Clin Immunol 1992; 89: 759-68.

7. Antico A. Oral allergy syndrome induced by chestnut (Castanea sativa). Ann Allergy Asthma Immunol 1996; 76: 37-40.

8. Beezhold DH, Sussman GL, Liss GM, Chang NS. Latex allergy can induce clinical reactions to specific foods. Clin Exp Allergy 1996; 26: 416-22.

9. Brehler R, Theissen U, Mohr C, Luger T. "Latex-fruit syndrome": frequency of cross-reacting antibodies. Allergy 1997; 52: 404-10.

10. DeMaat-Bleeker F, Stapel SO. Cross-reactivity between buckwheat and latex. Allergy 1998; 53: 538-9.

11. Focke M, Hemmer W, Wohrl S, et al. Cross-reactivity between Ficus Benjamina, latex and fig fruit in patients with clinical fig allergy. Clin Exp Allergy 2003; 33: 971-7. 
12. Dreborg S, Frew A. Allergen standardization and skin tests. Allergy 1993; 48: 49-54.

13. Ebo D, Bridts C, Verweij M, et al. Sensitization profiles in birch pollen-allergic patients with and without oral allergy syndrome: lessons from multiplexed component-resolved allergy diagnosis. Clin Exp Allergy 2010; 40: 339-47.

14. Ebo D, Hagendorens M, de Knop K, et al. Component-resolved diagnosis from latex by microarray. Clin Exp Allergy 2010; 40: 348-58

15. Ott H, Baron J, Heise R, et al. Clinical usefulness of microarray-based IgE detection in children with suspected allergy. Allergy 2008; 63: 1521-8.

16. Ott H, Schroder C, Raulf-Heimsoth M, et al. Microarrays of recombinant Hevea brasiliensis proteins: a new tool for the component-resolved diagnosis of natural rubber latex allergy. J Invest Allergol Clin Immunol 2010; 20: 129-38.

17. Scala E, Alessandri C, Bernardi M, et al. Cross-sectional survey on immunoglobulin E reactivity in 23077 subjects using an allergenic molecule-based microarray detection system. Clin Exp Allergy 2010; 40: 911-21.

18. Ott H, Folster-Holst R, Merk H, Baron J. Allergen microarrays: a novel tool for high-resolution IgE profiling in adults with atopic dermatitis. Eur J Dermatol 2010; 20: 54-61.

19. Ott H, Schroder C, Stanzel S, et al. Microarray-based IgE detection in capillary blood samples of patients with atopy. Allergy 2006; 61: 1146-52.

20. Raulf-Heimsoth M, Kespohl S, Crespo J, et al. Natural rubber latex and chestnut allergy: cross-reactivity or co-sensitization? Allergy 2007; 62: 1277-81.

21. Reindl J, Rihs H, Scheurer S, et al. IgE reactivity to profiling in pollen-sensitized subjects with adverse reations to banana and pineapple. Int Arch Allergy Immunol 2002; 128: 105-14.

22. Rihs H, Chen Z, Rozynek P, et al. PCR-based cloning, isolation and IgE-binding properties of recombinant latex profilin (rHev b 8). Allergy 2000; 55: 712-7. 